\title{
Structure and Properties of Membrane Surfaces of A-B-A Tri-Block Copolymers Consisting of Poly $(\gamma$-methyl D,L-glutamate) as the A Component and Polybutadiene as the B Component
}

\author{
Kouhei KUGO, ${ }^{*}{ }^{\dagger}$ Masatoshi Murashima, ${ }^{*}$ Toshio HaYASHI, ${ }^{* *}$ \\ and Akio NAKAJIMA*,** \\ *Department of Polymer Chemistry, Kyoto University, \\ Kyoto 606, Japan \\ ** Research Center for Medical Polymer and Biomaterials, \\ Kyoto University, Sakyo-ku, Kyoto 606, Japan
}

(Received September 16, 1982)

\begin{abstract}
A-B-A tri-block copolymers consisting of DL-isomers of poly( $\gamma$-methyl glutamate) as the $\mathrm{A}$ component and polybutadiene as the $\mathrm{B}$ component were prepared. The synthesis was carried out by polymerizing an equimolar mixture of $\gamma$-methyl D-glutamate and $\gamma$-methyl Lglutamate NCA with the amine groups capped at both ends of the polybutadiene block or the initiator. By infrared spectroscopy, it was found that the copolypeptide chain block exists not only in an $\alpha$-helical conformation but also in a random coil conformation. On the basis of contact angle measurements, replication electron micrographs, and attenuated total reflection-infrared spectra, it was concluded that the surface of the present block copolymer membranes has a microheterophase structure consisting of the copolypeptide and hydrophobic domains, and also has a grainy surface structure with a grain size of $300-500 \AA$. Furthermore, the adsorption of plasma proteins onto these block copolymer membranes was investigated.
\end{abstract}

KEY WORDS Tri-Block Copolymer / Poly $(\gamma$-methyl D,L-glutamate) / Polybutadiene / Contact Angle / Replication Electron Micrograph / Attenuated Total Reflection-Infrared Spectra /

In previous work, ${ }^{1}$ we investigated the preparation, molecular characterization, microheterophase structure, and surface characteristics of A-B-A triblock copolymers in which A was $\operatorname{poly}(\varepsilon-N$ benzyloxycarbonyl L-lysine) and $\mathbf{B}$ was polybutadiene.

Poly- $\alpha$-amino acids have been investigated for various biomedical materials, such as hemodialysis membranes and synthetic vascular prostheses. ${ }^{2-4}$ Block copolymers containing poly- $\alpha$-amino acid as one component should be excellent biomedical materials, since it has been reported by Lyman et al., ${ }^{5}$ Nyilas et al. ${ }^{6}$ and Okano et al. ${ }^{7}$ that the microheterophase structure characteristic of the block copolymers plays an important role in blood compatibility. In fact, biomembranes have a microhet- erophase structure composed of both hydrophilic and lipophilic domains. ${ }^{8}$ Anderson et al. ${ }^{9}$ carried out a study on the thrombogenic properties of AB-A tri-block copolymers consisting of $\operatorname{poly}(\gamma-$ benzyl L-glutamate) and random copolymer of butadiene-acrylonitrile, and suggest a definite correlation between the effect on thrombogenicity of morphological order and macromolecular motions with the initial adsorption of the blood elements.

Obviously, molecular studies of the surface characteristics of polymer membranes are indispensable to a discussion of such polymer-blood interactions. Merrill et al. ${ }^{10}$ investigated semiquantitatively the relation between the surface composition and thrombogenic potential of segmented polyurethanes

$\dagger$ Present address: Department of Applied Chemistry, Faculty of Science, Konan University, Okamoto 8-9-1, Higashinada-ku, Kobe 658, Japan. 


\section{K. Kugo et al.}

by Fourier transform IR internal reflection spectroscopy, X-ray photoelectron spectroscopy, and Auger electron spectroscopy. They found that the composition of these block copolymer membranes at the surface is not necessarily identical to that in the interior if the surface free energy is allowed to act. ${ }^{10,11}$ Nyilas et al. ${ }^{6,12}$ and Lyman et al. ${ }^{13}$ have suggested a relation between the surface free energy of segmented polyether-urethane membranes and plasma proteins adsorbed onto such membrane surfaces. It was pointed out that a balance between the polar and dispersion forces is important to thrombogenesis. Atsumi et al. ${ }^{14}$ recently examined the relation between the surface properties and blood compatibility of segmented polyurethanes, and emphasized the balance among the three components of the surface free energy of these block copolymer membranes, i.e., dispersion, polar, and hydrogen bonding forces. It was particularly noted that the component associated with hydrogen bonding is important to blood compatibility.

In this work, we discuss the preparation, structure, and surface characteristics of A-B-A tri-block copolymers consisting of DL-isomers of $\operatorname{poly}(\gamma-$ methyl glutamate) as the A component and polybutadiene as the $\mathrm{B}$ component. Conformation studies of poly ( $\gamma$-methyl D,L-glutamate) have been made by Masuda et $a l .{ }^{15}$ and Nakajima et al ${ }^{16}$ and show that the helical content in the membranes steadily decreases from $100 \%$ to $80 \%$ as the fraction of the Dresidue is increased from 0 to $50 \%$. Furthermore, these authors found that the helical content of the right-handed $\alpha$-helical form for poly $(\gamma$-methyl D,Lglutamate) in which D-residue is $50 \%$ equals the helical content of the left-handed form. Such perturbed $\alpha$-helical chains include $\mathrm{NH}$ and $\mathrm{CO}$ residues which are not incorporated in intramolecular hydrogen bonds of the $\alpha$-helix of a polypeptide backbone. Hence, in comparison with A-B-A tri-block copolymers in which $\mathrm{A}$ is a $\mathrm{L}$-isomer polypeptide, ${ }^{1}$ A-B-A tri-block copolymers in which $\mathrm{A}$ is a $\mathrm{D}, \mathrm{L}-$ isomer polypeptide are expected to contain more residues capable of intermolecular hydrogen bonding.

\section{EXPERIMENTAL}

\section{Materials}

Amine-Terminated Polybutadiene. The preparation and purification of the middle block, a cyclo- aliphatic secondary amine-terminated polybutadiene (ATPB), have been described in a previous paper. ${ }^{17}$ The ATPB was rich in trans isomers, having a number-average molecular weight, $M_{n}$ of 3600 .

$N$-Carboxy Anhydride of $\gamma$-Methyl D-glutamate and $\gamma$-Methyl L-glutamate. N-Carboxy anhydrides of $\gamma$-methyl D-glutamate and $\gamma$-methyl L-glutamate, i.e., $\gamma$-MDG NCA and $\gamma$-MLG NCA, respectively, were prepared by allowing $\gamma$-methyl $\mathrm{D}^{-}$and $\mathrm{L}^{-}$ glutamate monomers to react with phosgene, according to the method proposed by Blout. ${ }^{18}$ Both Dmonomer NCA and L-monomer NCA were recrystallized several times from ethyl acetate with petroleum ether.

Synthesis of Poly ( $\gamma$-methyl D,L-glutamate). The equimolar-D,L-copolypeptide, poly $(\gamma$-methyl D,Lglutamate) (PMDLG-55), was prepared by polymerizing an equimolar mixture of $\mathrm{D}$ - and $\mathrm{L}$-amino acid NCA in a dioxane-methylene dichloride $(1: 1$, $\mathrm{v} / \mathrm{v}$ ) mixture with triethylamine as the initiator. The copolypeptide obtained was fractionated with the system of methylene dichloride and methanol.

Synthesis of Block Copolymers. The amounts of ATPB and an equimolar mixture of $\gamma$-MDG and $\gamma$ MLG NCA needed to obtain the desired degree of polymerization for the polypeptide block were dissolved in a dioxane-methylene dichloride $(1: 2$, $\mathrm{v} / \mathrm{v})$ mixture at a total concentration $3 \mathrm{wt} \%$ amino acid-NCA and ATPB. The polymerization was carried out at $25^{\circ} \mathrm{C}$ for $72 \mathrm{~h}$, and the resulting copolymer was precipitated by 5 volumes of pure cold methanol, and dried in vacuo. The fractionation was carried out by dissolving the copolymer in a mixture of chloroform and $n$-hexane and using ethanol as a precipitant. Four to five fractions were separated and their central portions were used for the measurements. These A-B-A tri-block copolymers are abbreviated as MBM-[DL].

\section{Measurements}

Composition of Block Copolymers. The molar composition of the present block copolymers was determined by elemental analysis and the numberaverage molecular weight of ATPB. The elemental analysis was carried out at the Organic Microanalysis Center in Kyoto University. Since the number-average molecular weight of the middle block was known, the degree of polymerization of the A block chain $P_{\mathrm{A}}$ was estimated from the 
copolymer composition. In Table I, the copolymer composition expressed in $\mathrm{mol} \%$ of the A component is summarized along with $P_{\mathrm{A}}$.

Molecular Weights. The molecular weights of the present A-B-A tri-block copolymers were estimated from the results of elemental analysis and the number-average molecular weight, $M_{n}=3600$, of ATPB. The molecular weights obtained were, therefore, the number-average molecular weights. The molecular weight of PMDLG-55 was determined from the limiting viscosity number $[\eta]$ in dichloroacetic acid (DCA) using the $[\eta]$ vs. $M_{n}$ relationship ${ }^{19}$ proposed for poly $(\gamma$-methyl L-glutamate) (PMLG). DCA is a coil solvent not only for PMLG but also for PMDLG. ${ }^{20}$

Infrared Spectra. Infrared (IR) spectra were obtained with a Hitachi 260-30 IR spectrophotometer equipped with a Hitachi 260-0260 Data Processor. To investigate the chain conformation of polypeptide blocks in the solid state, IR spectra of solid membranes ( $4 \mu \mathrm{m}$ in thickness) cast from a $10: 1$ $(\mathrm{v} / \mathrm{v})$ mixture of chloroform (CF) and 2,2,2-trifluoroethanol (TFE) were measured in a region from 4000 to $400 \mathrm{~cm}^{-1}$.

Attenuated total reflection-infrared (ATR-IR) spectra were obtained using a KRS-5 reflection plate at an incidence angle of $70^{\circ}$ with a Hitachi MIR-5 multiple internal reflection attachment placed in the sample compartment of the IR spectrometer. The KRS-5 reflection plate was cleaned in carbon tetrachloride before each spectral measurement. For ATR-IR measurements, membranes $30 \mu \mathrm{m}$ thick were cast onto glass plates from a 10:1 CF-TFE mixture at $25^{\circ} \mathrm{C}$ and a relative humidity less than $65 \%$. The membranes were dried in vacuo at room temperature before use.

Contact Angle. Contact angle measurements were made at $20^{\circ} \mathrm{C}$ using a Shimadzu Model ST-1 Surface Tensometer which utilizes the Wilhelmy method. ${ }^{21}$ Sample were dissolved in a 10:1 (v/v) mixture of CF and TFE. The polymer film was prepared by slowly evaporating the solvent on the glass plate at $25^{\circ} \mathrm{C}$ and at a relative humidity less than $65 \%$. The sample film was dried in vacuo at room temperature for $24 \mathrm{~h}$ before use. The contact angle was calculated from the experimental values of the advancing and receding contact angles using Adam's equation. ${ }^{22}$ The experimental values used were the averages on at least five films prepared independently.
Electron Microscopy. The microheterophase structure of the present A-B-A tri-block copolymers was investigated by a Hitachi H-500 High Resolution Transmission Electron Microscope. The accelerating voltage was $75 \mathrm{kV}$. The polymer samples were dissolved in a $10: 1(\mathrm{v} / \mathrm{v})$ mixture of $\mathrm{CF}$ and TFE. An aliquot copolymer solution was dispersed onto the sheet mesh of the electron microscope equipped with a collodion and carbon membrane, and allowed to form a thin membrane. To avoid a rapid evaporation of the solvent, these thin membranes were prepared at $25^{\circ} \mathrm{C}$ in an atmosphere of the solvent. The membrane was then treated by the osmium tetroxide fixation technique developed by Kato. ${ }^{23}$ The membrane was stained with saturated vapor of a $4 \% \mathrm{OsO}_{4}$ aqueous solution at room temperature for $24 \mathrm{~h}$ and dried in vacuo for $24 \mathrm{~h}$ before use. The polybutadiene (PB) domain was selectively stained by $\mathrm{OsO}_{4}$ because of the unsaturated olefinic $\mathrm{C}=\mathrm{C}$ double bonds contained in this domain. ${ }^{1}$

The surface morphology of polymer membranes was examined by the three-stage replica technique with a transmission microscope. Specimens were first coated with poly(vinyl alcohol) (PVA) from an aqueous solution, and the PVA replicas were further replicated by acetylcellulose films (AC) using methyl acetate. Finally, the AC replica was shadowed with platinum/palladium $(\mathrm{Pt} / \mathrm{Pd}=80 / 20)$ at an angle of about $30^{\circ}$, and backed with carbon in a vacuum evaporator. The carbon-Pt/Pd replica was obtained by dissolving the AC in methyl acetate. The replicas were examined under a Hitachi H-500 High Resolution Transmission Electron Microscope. Moreover, in order to confirm whether the surface of polymer membranes was concave or convex, an aqueous polystyrene emulsion was sprayed over the surface of the AC replicas before shadowing $\mathrm{Pt} / \mathrm{Pd}$.

Adsorption of Plasma Protein. Bovine serum albumin (BSA) (Sigma Chemical Co.) and bovine fibrinogen (BF) (Povite Inc.) were dissolved in $0.05 \mathrm{M}$ of a phosphate buffer solution of $\mathrm{pH} 7.4$ at concentrations of $0.09 \mathrm{~g} \mathrm{dl}^{-1}$ and $0.05 \mathrm{~g} \mathrm{dl}^{-1}$, respectively. These concentrations were determined using $E_{279 \mathrm{~nm}}^{1 \%}=6.67$ for $\mathrm{BSA}^{24}$ and $E_{280 \mathrm{~nm}}^{0.1 \%}=1.506$ for $\mathrm{BF}^{25}$ by a Hitachi Spectrophotometer Model EPS-3T. MBM-[DL] block copolymer membranes, (30 $\mathrm{nm}$ in thickness), cast from a $10: 1(\mathrm{v} / \mathrm{v}) \mathrm{CF}-$ TFE mixture and dried in vacuo before use, were 
immersed in the protein solution at $37^{\circ} \mathrm{C}$ for $2 \mathrm{~h}$. The protein solution was discarded by decantation, and the film was rinsed repeatedly with a $100 \mathrm{ml}$ phosphate buffer solution $(0.05 \mathrm{M}, \mathrm{pH} 7.4)$ and distilled water. The sample membranes were then dried in vacuo at room temperature for $2 \mathrm{~h}$.

\section{RESULTS AND DISCUSSION}

\section{Materials}

The composition of block copolymers and $P_{\mathrm{A}}$ are summarized together with the molecular weight in Table I. For a comparison with MBM-[DL] series, the molecular parameters of MBM series evaluated in a previous paper, ${ }^{26}$ are also listed in Table I. MBM stands for an A-B-A type tri-block copolymer consisting of PMLG as the A component and $\mathrm{PB}$ as the $\mathrm{B}$ component. It can be seen from the composition in Table I that MBM-[DL]-1 and

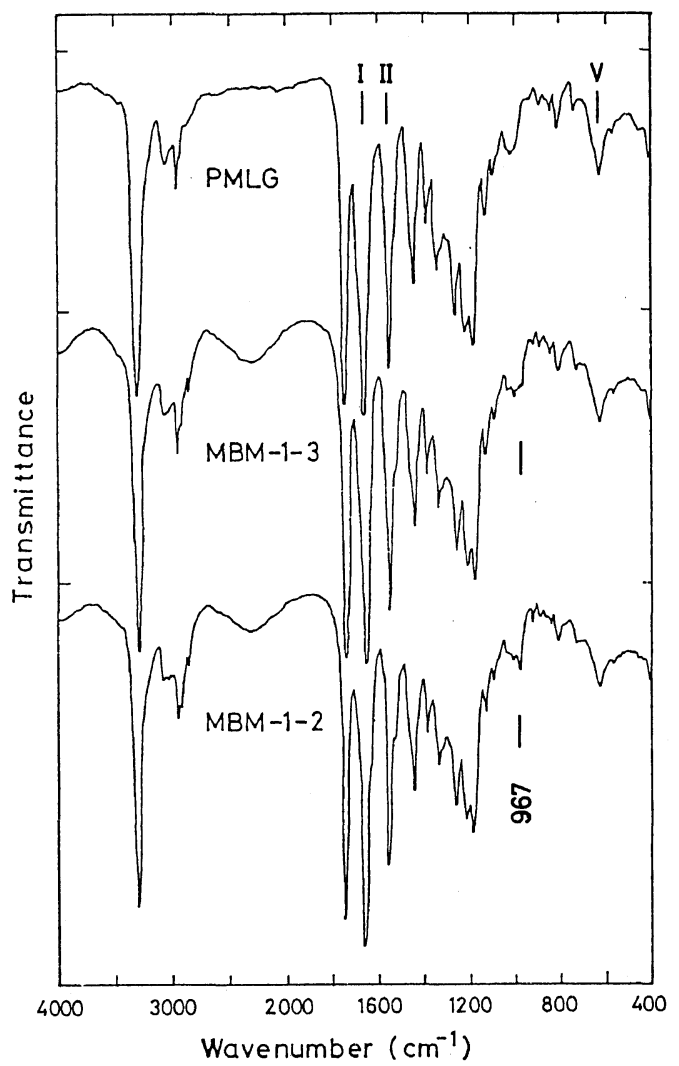

MBM-[DL]-2 are comparable with MBM-1-2 and MBM-1-3, respectively.

Table I. Molecular characterization of A-B-A tri-block copolymers consisting of polypeptide (A) and polybutadiene (B)

\begin{tabular}{lrrr}
\hline \multirow{1}{*}{ Designation } & \multicolumn{1}{c}{$\mathrm{A}$} & & \\
\cline { 2 - 3 } & $\mathrm{mol} \%$ & $\mathrm{P}_{\mathrm{A}}$ & $\mathrm{M} . \mathrm{W} . \times 10^{-4}$ \\
& 66.4 & 73 & 2.4 \\
MBM-[DL]-1 & 84.4 & 122 & 3.9 \\
MBM-[DL]-2 & 100.0 & 412 & 11.8 \\
PMDLG-55 & 56.7 & 40 & 1.5 \\
MBM-1-1 & 68.1 & 65 & 2.2 \\
MBM-1-2 & 80.3 & 124 & 3.9 \\
MBM-1-3 & 90.9 & 305 & 9.1 \\
MBM-1-4 & 100.0 & 429 & 12.3 \\
PMLG & & & \\
\hline
\end{tabular}

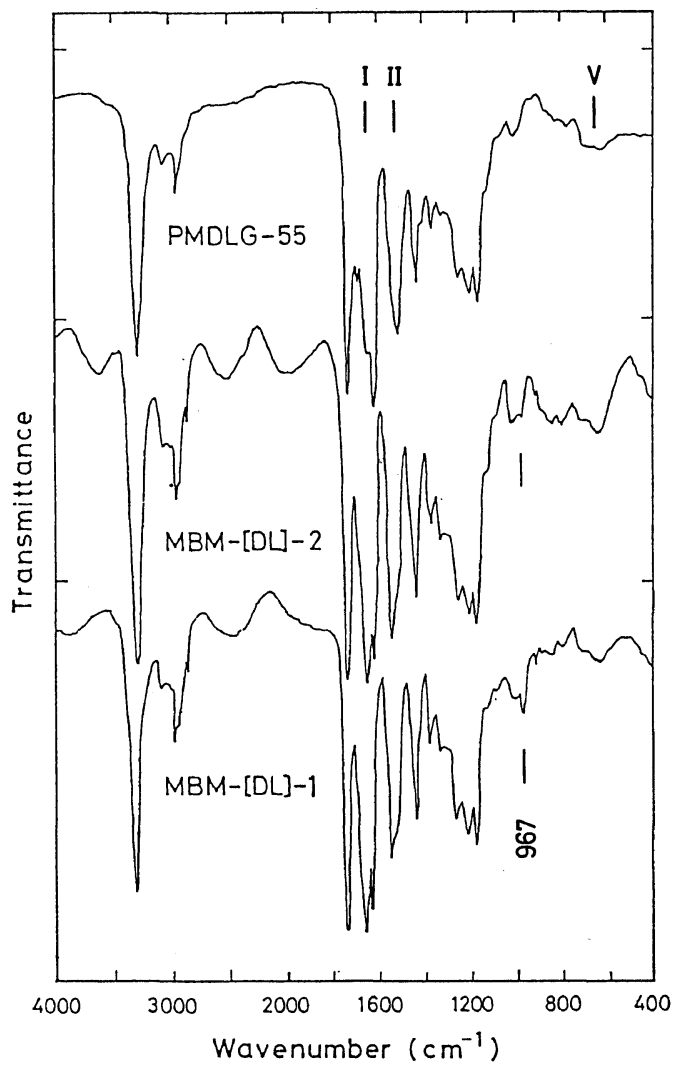

Figure 1. Infrared spectra of unoriented membranes of PMLG, PMDLG, MBM, and MBM-[DL] cast from a $10: 1 \mathrm{CF}-\mathrm{TFE}$ mixture. 
Chain Conformation of Copolypeptide in Solid State

IR spectra of MBM-[DL], MBM, PMDLG-55, and PMLG in the region from 4000 to $400 \mathrm{~cm}^{-1}$ are shown in Figure 1. Figure 1 indicates that amide I, II, and $\mathrm{V}^{27}$ bands of these MBM block copolymers appear at 1650,1545 , and $615 \mathrm{~cm}^{-1}$, respectively, as is the case for the PMLG homopolymer. This implies that the M-block component in the MBM block copolymers assumes an $\alpha$-helical conformation and that the helical content of MBM block copolymers is nearly the same as that of PMLG homopolymers. A specific band associated with the $\mathrm{C}=\mathrm{C}$ torsion and the $\mathrm{CH}$ out-of-plane band modes $^{28}$ was observed at around $967 \mathrm{~cm}^{-1}$, and the relative intensity of this band increased with an increase in mol percent of polybutadiene in MBM block copolymers, as expected.

For MBM-[DL] block copolymers, the peak of the amide $I$ band split into two peaks at $1650 \mathrm{~cm}^{-1}$ and $1625 \mathrm{~cm}^{-1}$, and the strong peak at $1545 \mathrm{~cm}^{-1}$ of the amide II band exhibited a shoulder at around 1540 to $1520 \mathrm{~cm}^{-1}$. Furthermore, the amide $\mathrm{V}$ band for MBM-[DL] block copolymers, as well as that for PMDLG-55, exhibited a broad peak at around 640 $\mathrm{cm}^{-1}$, and the intensity was lower than that of the

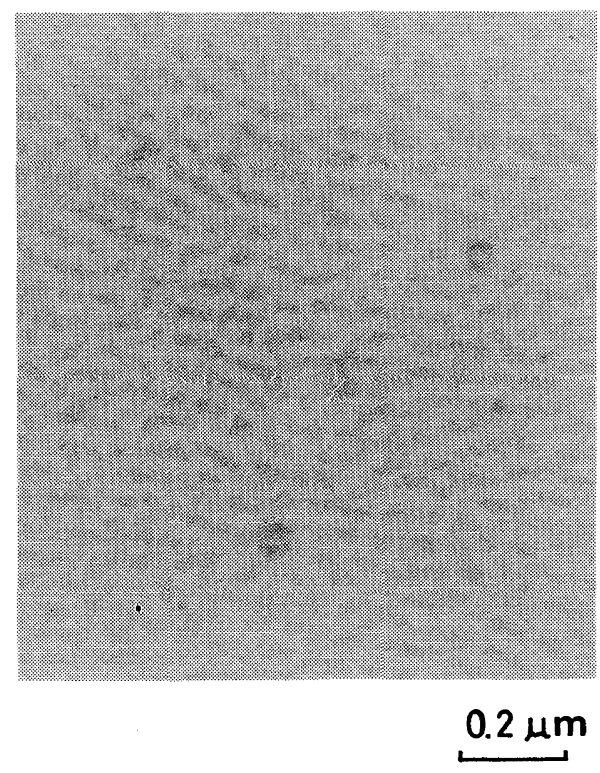

(1) $M B M-[D L]-1$ corresponding L-isomeric polymers. These results indicate that most of the PMDLG block chains in the MBM-[DL] block copolymers as well as PMDLG-55 assume the $\alpha$-helical conformation, but some portions are in random coil conformation. As in the corresponding L-isomeric block copolymers, ${ }^{26}$ a specific band associated with the $\mathrm{C}=\mathrm{C}$ torsion and the $\mathrm{CH}$ out-of-plane band modes $^{28}$ was observed around $967 \mathrm{~cm}^{-1}$, and the relative intensity of this band increases with an increased in mole percent of polybutadiene in MBM-[DL] block copolymers, as expected.

\section{Bulk Morphology}

Information on the domain structure of the present block copolymers in the solid state was obtained from electron microscopic observations of the morphology of MBM-[DL] block copolymers in the film state. Some of the electron micrographs are shown in Figure 2. The dark portions in these photographs correspond to the domains composed of polybutadiene chains stained with osmium tetroxide. A cylindrical structure was seen for MBM[DL]-1 (Figure 2(1)) and a spherical structure for MBM-[DL]-2 (Figure 2(2)). The micelle dimensions

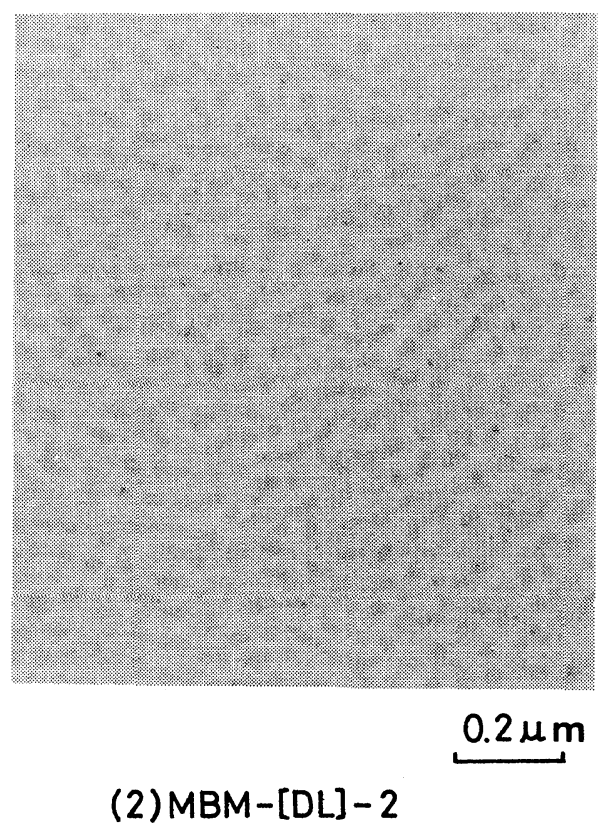

Figure 2. Electron micrographs of MBM-[DL] block copolymer membranes cast from a 10:1 CF-TFE mixture at $25^{\circ} \mathrm{C}$ : (1) MBM-[DL]-1; (2) MBM-[DL]-2. 
$D_{\mathrm{EM}}$ defined previously ${ }^{29}$ were estimated from electron micrographs to be $380 \AA$ for MBM-[DL]-1 and $460 \AA$ for MBM-[DL]-2.

\section{Wettability}

The surface characteristics of the block copolymer membrane were investigated by measuring the contact angle $\theta$ of various liquids on the sample

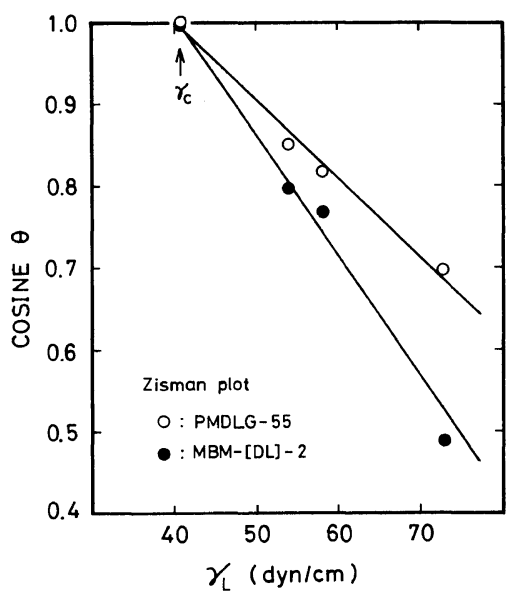

Figure 3. Wettability of PMDLG-55 and MBM-[DL]-2 membrane surfaces by various liquids: (O) PMDLG-55; (O) MBM-[DL]-2. membranes at $20^{\circ} \mathrm{C}$. Figure 3 shows Zisman's plots $^{30}$ of $\cos \theta v s$. the surface tension $\gamma_{L}$ of various liquids for PMDLG-55 and MBM-[DL]-2. Analysis of the data of Figure 3 by the least-squares method gave critical surface tensions $\gamma_{C}$ of $40 \mathrm{dyn} \mathrm{cm}^{-1}$ for PMDLG-55 and $41 \mathrm{dyn} \mathrm{cm}^{-1}$ for MBM-[DL]-2. These values are considered to be reasonable, since it is reported by Zisman et al. ${ }^{31}$ that the critical surface tension for polyamides is in the range of 40

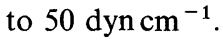

It can be seen from Figure 3 that the wettability of an MBM-[DL] membrane for hydrogen bonding liquids is less than that of a PMDLG-55 membrane. The value of $\gamma_{c}$ for poly(trans-1,4-butadiene), as the B component of MBM-[DL] block copolymers, has been reported as $31 \mathrm{dyn} \mathrm{cm}^{-1}$ by Lee. ${ }^{32}$ Therefore, $\mathrm{PB}$ as the $\mathrm{B}$ component is more hydrophobic than PMDLG as the A component. This may explain the poor wettability of MBM-[DL] block copolymer membranes for hydrogen bonding liquids. Thus, the PB domains should exist in the outermost surface portion of MBM-[DL] block copolymer membranes.

\section{Surface Morphology}

Figure 4 shows the replication electron micrographs of the membrane surfaces of the MBM-

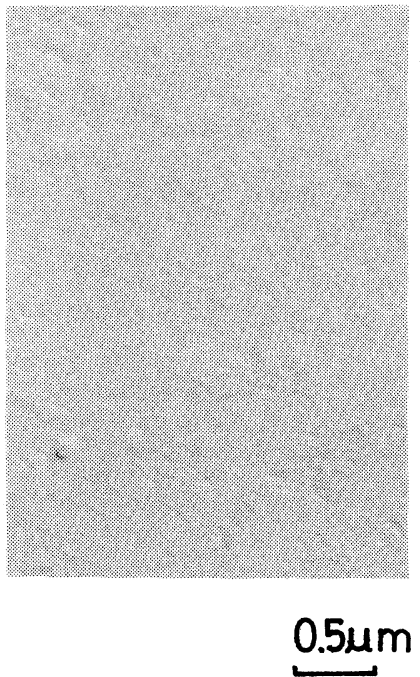

(1) PMDLG - 55

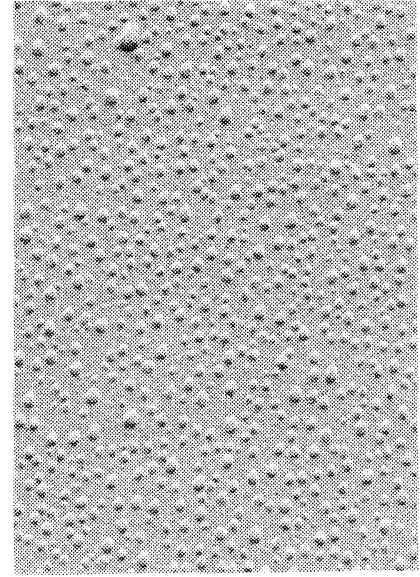

$0.5 \mu \mathrm{m}$

(2) $M B M-[D L]-2$

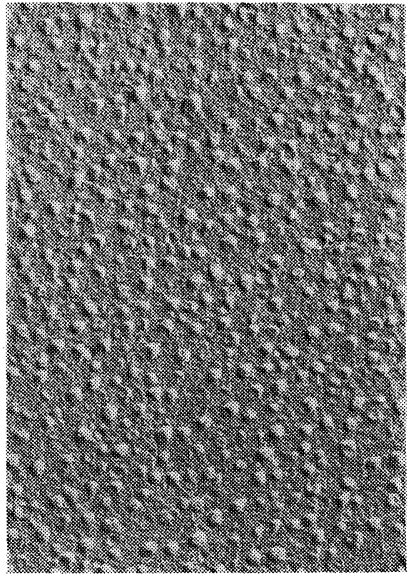

$0.5 \mu \mathrm{m}$

Figure 4. Replication electron micrographs of the membrane surfaces of: (1) PMDLG-55; (2) MBM[DL]-2; (3) MBM-[DL]-1. 
[DL] block copolymer and PMDLG-55. The surface of the PMDLG-55 membrane is almost smooth, whereas those of the MBM-[DL] block copolymer membranes are coarse. The distinct black portion in the photographs is polystyrene emulsion particles. The direction of its shadow indicates that the circular parts on the surface of the MBM-[DL] membranes are convex above a relatively flat matrix.

Vanzo $^{33}$ reported that the surface replucas of A-B di-block copolymer membranes exhibit layered structures with various orientations. Recently, Brash et $a l^{34}$ reported that the surface replicas of segmented polyurethane membranes show a uniformly grainy surface structure with grain sizes from 100 to $200 \AA$. Furthermore, O'Malley et al. $^{35}$ pointed out from an X-ray photoelectron spectroscopic study that the surfaces of A-B di-block copolymers composed of polystyrene and polyethyleneoxide are nonplanar and that the polystyrene domains are located above the polyethyleneoxide domains.

From these results along with the size (300$500 \AA$ ) of the convex domains and the molar composition of MBM-[DL] block copolymers, it may be inferred that the convex domains of PB are dispersed on the planar matrix phase of PMDLG.

\section{Surface Characteristics of MBM-[DL] Block Copolymer Membranes \\ In order to obtain more information on the}

surface properties of the present tri-block copolymer membranes, we further investigated the chemical composition of these membrane surfaces by ATR-IR spectroscopy. According to internal reflection spectroscopy, the depth of IR beam penetration $d_{\mathrm{p}}$ at a wavelength $\lambda$ can be estimated from $^{36}$

$$
d_{\mathrm{p}}=\frac{\lambda}{2 \pi n_{1}\left(\sin ^{2} \theta-n_{21}^{2}\right)^{1 / 2}}
$$

where $n_{1}$ is the refractive index of the reflection plate ( 2.37 for KRS-5), $n_{21}=n_{2} / n_{1}=0.63$ by assuming $n_{2}$ to be 1.50 for MBM-[DL] block copolymers, and $\theta$, the effective incident angle, of $70^{\circ}$ in the present experiment. The relation between $d_{\mathrm{p}}$ and $1 / \lambda$ is shown in Figure 5. This figure shows that, for analysis of the chemical composition of the MBM[DL] block copolymer surfaces, it is desirable to compare absorption peaks close to each other so as to minimize error caused by the difference in $d_{\mathrm{p}}$ as a function of $1 / \lambda$. In the present systems, therefore, a peak at $967 \mathrm{~cm}^{-1}$ is used as an index for B block concentration, and $1735,1650,1545$, and 1170 $\mathrm{cm}^{-1}$ are used as indices for A block concentration, which are associated with $\mathrm{C}=\mathrm{O}$ stretching vibration of the ester, amide $\mathrm{I}$, amide $\mathrm{II}$, and $\mathrm{C}-\mathrm{O}$ stretching vibration of the ester, respectively. Thus, $d_{\mathrm{p}}$ ranged from 0.56 to $1.00 \mu \mathrm{m}$, as shown by the dashed lines in Figure 5.

Figure 6 shows the ATR-IR spectra of both air facing and glass facing surfaces of MBM-[DL] and

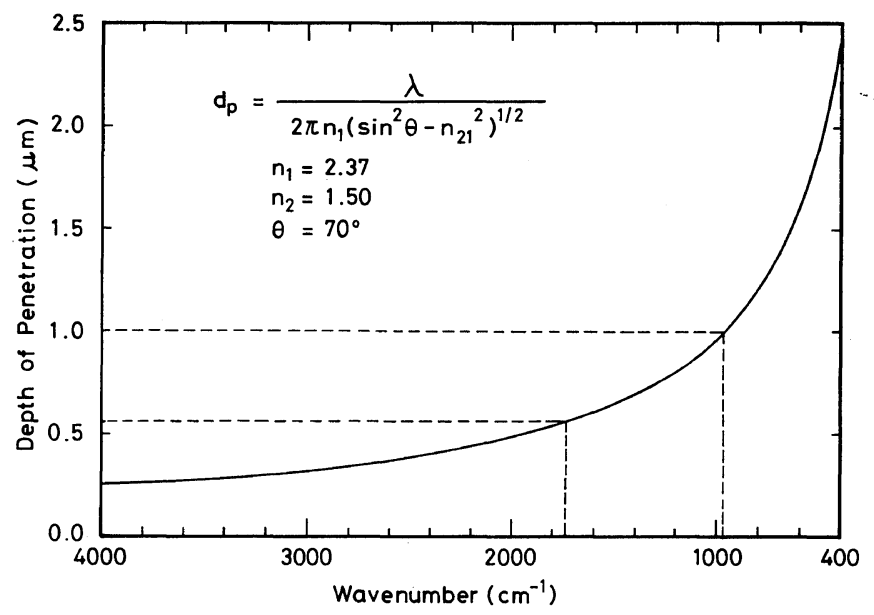

Figure 5. Theoretical depth of IR beam penetration as a function of wave number with KRS-5 reflection plate at the incident angle of $70^{\circ}$. 


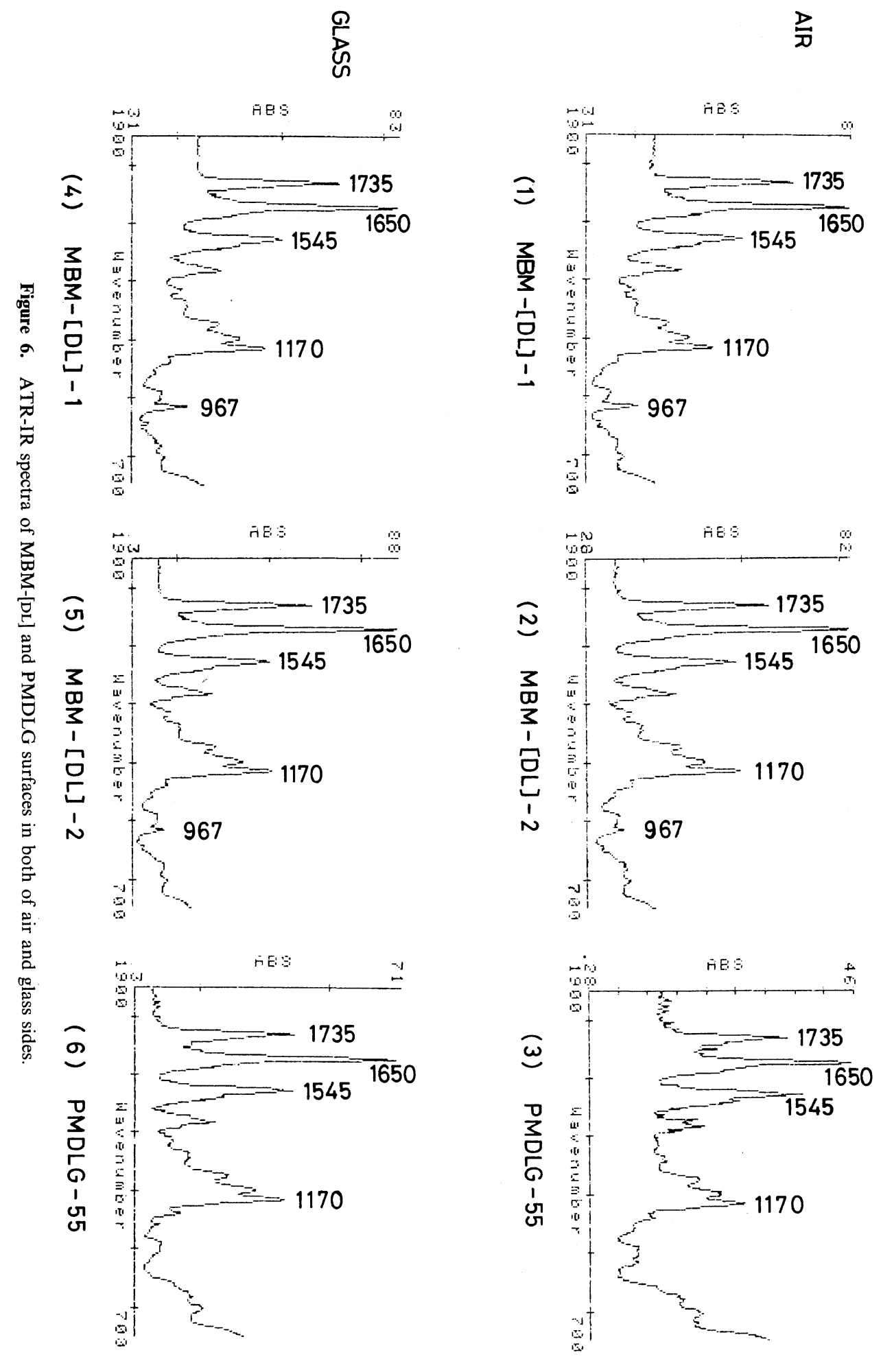


PMDLG-55. All spectra exhibited peaks at 1735 $\mathrm{cm}^{-1}$ (ester), $1650 \mathrm{~cm}^{-1}$ (amide I), $1545 \mathrm{~cm}^{-1}$ (amide II), and $1170 \mathrm{~cm}^{-1}$ (ester), as expected. The relative intensity of the band at $967 \mathrm{~cm}^{-1}$ decreases

Table II. Absorbance area ratios of block copolymer surfaces

\begin{tabular}{ccc}
\hline $\begin{array}{c}\text { Absorbance area } \\
\text { ratio }\end{array}$ & \multicolumn{2}{c}{ Air side } \\
\cline { 2 - 3 } cm $^{-1}$ & \multicolumn{2}{c}{ Glass side } \\
\hline Butadiene/Peptide & MBM-[DL]-1 & MBM-[DL]-2 \\
A 967/A 1735 & 1.05 & 1.15 \\
A 967/A 1650 & 1.08 & 1.14 \\
A 967/A 1545 & 1.10 & 1.12 \\
A 967/A 1170 & 1.08 & 1.13 \\
\hline
\end{tabular}

BSA

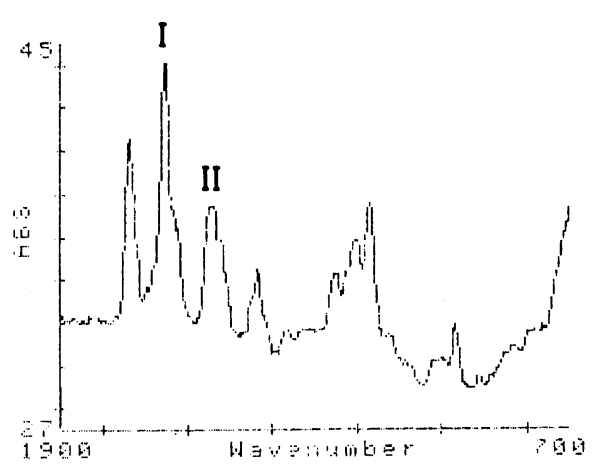

(1) $\mathrm{MBM}-[\mathrm{DL}]-1$

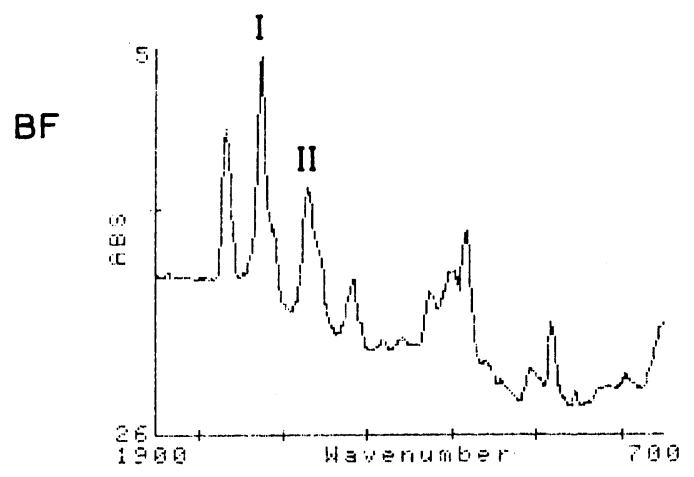

(3) $\mathrm{MBM}-[D L]-1$ with a decrease in mole percent of the $B$ block domain in MBM-[DL] block copolymers, and reduces to zero for PMDLG-55. The spectra of air and glass facing MBM-[DL] block copolymer surfaces are basically similar, but the relative concentration of A block and B block estimated from the absorbance ratios of the characteristic peaks is different for the two surfaces, as can be seen from Table II. In this estimation, the absorbance area ratio rather than the absorbance height ratio was used, since both the $\alpha$-helical and disordered forms partly overlap each other in these amide bands as described above. As indicated in Table II, there is an excess of the B block (PB) concentration in the air facing surface for both membranes. This result is reasonable if the surface free energy is allowed to act.

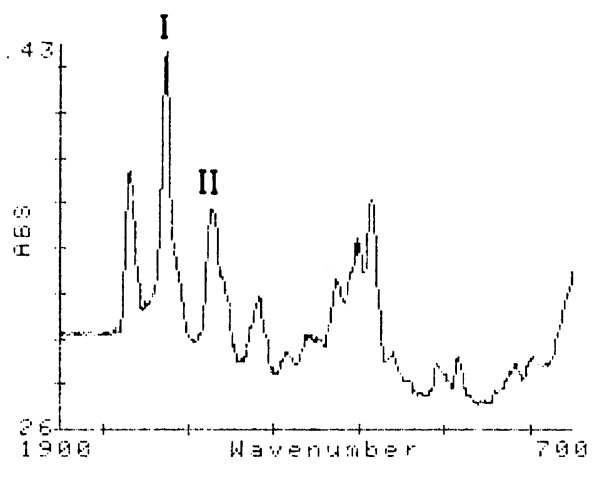

(2)

$M B M-[D L]-2$

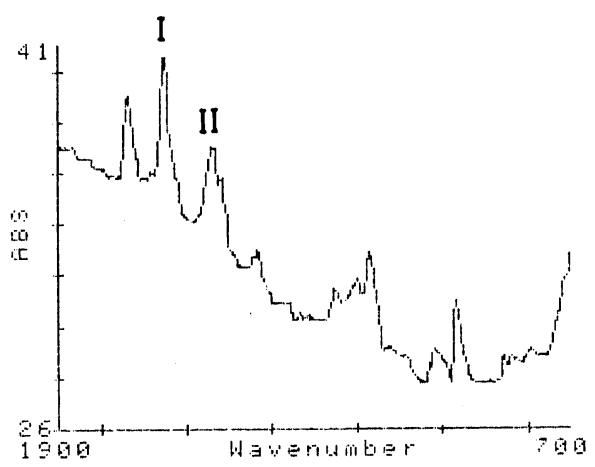

(4) $M B M-[D L]-2$

Figure 7. ATR-IR spectra of air-side surfaces of MBM-[DL] block copolymer membranes exposed to BSA and BF solutions. 
Adsorption of Plasma Protein on the Surface of Block Copolymer Membranes

The infrared spectra of proteins have been widely studied. ${ }^{37,38}$ The characteristic absorption bands of proteins are the amide $\mathrm{A}$ band due to the $\mathrm{N}-\mathrm{H}$ group at $3300 \mathrm{~cm}^{-1}$, and the amide I and amide II bands due to the -CONH- group at $1650 \mathrm{~cm}^{-1}$ and $1545 \mathrm{~cm}^{-1}$. Since the MBM-[DL] block copolymer includes a polypeptide as the A component, the ATR-IR peaks characteristic of the polypeptide and those of plasma proteins adsorbed onto the surface of MBM-[DL] block copolymer membranes partly overlap each other. The distinction of those peaks among those membranes is therefore considered to be difficult. Figure 7 shows the ATR-IR spectra for MBM-[DL] air-facing surfaces exposed to BSA and BF solutions. The important peaks of these spectra are located at the same position as in the spectra for the free surfaces. This fact indicates that the plasma proteins, BSA and BF, are not denatured when adsorbed onto the surface of MBM-[DL] block copolymer membranes. It is reported $^{39}$ that the BSA molecule is not denatured when physically adsorbed on some polymeric surfaces. Hence, it may be concluded that the surfaces of MBM-[DL] membranes have only weak or easily reversible interactions with these plasma pro teins.

Our contact angle measurements, replication electron micrographs, and ATR-IR spectra all show that the surface of the present MBM-[DL] block copolymer membranes has a microheterophase structure consisting of both hydrophilic PMDLG and hydrophobic PB domains, and also a grainy surface structure with a grain size of $300-500 \AA$, which is comparable to the dimensions of plasma proteins. ${ }^{40,41}$ These structures may result in good compatibility of MBM-[DL] block copolymer membranes with blood elements. These membranes may thus find important applications in various fields of biomedical interest.

Acknowledgments. We wish to thank Dr. K. Rieu and Dr. R. Drake, the B. F. Goodrich Chem. Co., for kindly supplying the amine-terminated polybutadiene. We also extend our appreciation to Mr. S. Yamaguchi, Central Research Laboratory, Daikin Kogyo Co., for assisting with electron microscopy.

\section{REFERENCES}

1. K. Kugo, T. Hayashi, and A. Nakajima, Polym. J., 14, 391, 401 (1982).

2. E. Klein, P. D. May, J. K. Smith, and N. Leger, Biopolymers, 10, 647 (1971).

3. E. C. Martin, P. D. May, and W. A. McMahon, J. Biomed. Mater. Res., 5, 53 (1971).

4. J. M. Anderson, D. F. Gibbons, R. L. Martin, A. Hiltner, and R. Woods, J. Biomed. Mater. Res. Symp., 5, 197 (1974).

5. D. J. Lyman, K. Knutson, B. McNeill, and K. Shibatani, Trans. Am. Soc. Artif. Int. Organs, 21, 49 (1975).

6. E. Nyilas, W. A. Morton, D. M. Lederman, T-H. Chiu, and R. D. Cumming, Trans. Am. Soc. Artif. Int. Organs, 21, 55 (1975).

7. T. Okano, S. Nishiyama, I. Shinohara, T. Akaike, and Y. Sakurai, Polym. J., 10, 223 (1978); T. Okano, S. Nishiyama, I. Shinohara, T. Akaike, Y. Sakurai, K. Kataoka, and T. Tsuruta, J. Biomed. Mater. Res., 15, 393 (1981).

8. P. N. Sawyer, C. Burrowes, J. Ogoniak, A. O. Smith, and S. A. Wesolowski, Trans. Am. Soc. Artif. Int. Organs, 10, 316 (1964).

9. S. A. Barenberg, J. S. Schultz, J. M. Anderson, and P. H. Geil, Trans. Am. Soc. Artif. Intern. Organs, 25, 159 (1979); S. A. Barenberg, J. M. Anderson, and K. A. Mauritz, J. Biomed. Mater. Res., 15, 231 (1981).

10. C. S. Paik Sung, C. B. Hu, E. W. Merrill, and E. W. Salzman, J. Biomed. Mater. Res., 12, 791 (1978); C. S. Paik Sung and C. B. Hu, ibid., 13, 45, 161 (1979); V. Sa Da Costa, D. Brier-Russell, E. W. Salzman, and E. W. Merrill, J. Colloid Interface Sci., 80,

11. V. Sa Da Costa, D. Brier-Russell, G. Turdel III, D. F. Waugh, E. W. Salzman, and E. W. Merrill, J. Colloid Interface Sci., 76, 594 (1980); C. S. Paik Sung and C. B. Hu, J. Biomed. Mater. Res., 13, 161 (1979).

12. E. Nyilas, W. A. Morton, R. D. Cumming, D. M. Lederman, and T-H. Chiu, J. Biomed. Mater. Res. Symp., 8, 51 (1977).

13. A. Baszkin and D. J. Lyman, J. Biomed. Mater. Res., 14, 393.(1980).

14. K. Furusawa, Y. Shimura, K. Otobe, K. Atsumi, and K. Tsuda, Kobunshi Ronbunshu, 34, 309 (1977).

15. Y. Masuda, T. Miyazawa, and M. Goodman, Biopolymers, 8, 515 (1969).

16. A. Nakajima, T. Hayashi, K. Itoh, and T. Fujiwara, Polym. J., 4, 10 (1973); T. Hayashi, K. Kugo, and A. Nakajima, Rep. Prog. Polym. Phys., Jpn., 21, 581 (1978).

17. A. Nakajima, T. Hayashi, K. Kugo, and K. Shinoda, Macromolecules, 12, 840 (1979).

18. E. R. Blout and R. H. Karlson, J. Am. Chem. Soc., 78, 941 (1956).

19. S. Tanaka and A. Nakajima, Bull. Inst. Chem. Res. Kyoto Univ., 54, 229 (1976). 
20. P. Doty, J. Am. Chem. Soc., 79, 3961 (1957).

21. L. Wilhelmy, Ann. Physik Chem., 119, 177 (1863).

22. N. K. Adam and G. Jessop, J. Chem. Soc., 127, 1863 (1925).

23. K. Kato, Polym. Lett., 4, 35 (1966); Polym. Eng. Sci., 7, 38 (1967); Polymer, 9, 225 (1968); ibid., 9, 419 (1968).

24. J. F. Foster, M. Sogami, H. A. Petersen, and W. J. Leonard, Jr., J. Biol. Chem., 240, 2495 (1965); V. R. Zurawski, Jr., W. J. Kohr, and J. F. Foster, Biochemistry, 14, 5579 (1975).

25. E. Mihalyi, Biochemistry, 7, 208 (1968).

26. T. Hayashi, K. Kugo, and A. Nakajima, Rep. Prog. Polym. Phys., Jpn., 25, 687 (1982).

27. T. Miyazawa and E. R. Blout, J. Am. Chem. Soc., 83, 712 (1961); T. Miyazawa, Y. Masuda, and K. Fukushima, J. Polym. Sci., 62, S62 (1962).

28. S. L. Hsu, W. H. Moore, and S. Krimm, J. Appl. Phys., 46, 4185 (1975).

29. A. Nakajima, K. Kugo, and T. Hayashi, Macromolecules, 12, 844 (1979).

30. H. W. Fox and W. A. Zisman, J. Colloid Sci., 5, 514 (1950); W. A. Zisman, "Contact Angle, Wettability and Adhesion," Adv. Chem. Ser., No. 43 (1964).
31. R. E. Baier and W. A. Zisman, Macromolecules, 3, 70, 462 (1970); A. H. Ellison and W. A. Zisman, $J$. Phys. Chem., 58, 503 (1954); G. I. Loeb and R. E. Baier, J. Colloid Interface Sci., 27, 38 (1968).

32. L.-H. Lee, J. Polym. Sci., A-2, 5, 1103 (1967).

33. E. Vanzo, J. Polym. Sci., A-1, 4, 1727 (1966); ibid., $A-1,6,1661$ (1968); ibid., C, 26, 161 (1969).

34. J. L. Brash and S. Uniyal, J. Polym. Sci., Polym. Symp., 66, 377 (1979).

35. H. R. Thomas and J. J. O'Malley, Macromolecules, 12, 323 (1979).

36. N. J. Harrick, "Internal Reflection Spectroscopy," Wiley, New York, N.Y., 1967, p 30.

37. A. Elliott and E. M. Bradbury, J. Mol. Biol., 5, 574 (1962); Polymer, 4, 47 (1963).

38. M. Beer, G. B. B. M. Sutherland, K. N. Tanner, and D. L. Wood, Proc. R. Soc. London, Ser. A, 249, 147 (1959).

39. B. W. Morrissey and R. R. Stronberg, J. Colloid Interface Sci., 46, 152 (1974).

40. J. L. Oncley, G. Scatchard, and A. Brown, J. Phys. Colloid Chem., 51, 134 (1947).

41. J. L. Brash and D. J. Lyman, J. Biomed. Mater. Res., 3, 175 (1969). 